\title{
Diagnosis features of pediatric Gaucher disease patients in the era of enzymatic therapy, a national-base study from the Spanish Registry of Gaucher Disease
}

Marcio Andrade-Campos 1,2,3, Pilar Alfonso 2,3, Pilar Irun²,3, Judith Armstrong ${ }^{4}$, Carmen Calvo ${ }^{5}$, Jaime Dalmau ${ }^{6}$, Maria-Rosario Domingo ${ }^{7}$, Jose-Luis Barbera ${ }^{8}$, Horacio Cano ${ }^{9}$, Maria-Angeles Fernandez-Galán ${ }^{10}$, Rafael Franco ${ }^{11}$, Inmaculada Gracia ${ }^{12}$, Miguel Gracia-Antequera ${ }^{13}$, Angela Ibañez ${ }^{14}$, Francisco Lendinez ${ }^{15}$, Marcos Madruga ${ }^{16}$, Elena Martin-Hernández ${ }^{17}$, Maria del Mar O'Callaghan ${ }^{18}$, Alberto Pérez del Soto ${ }^{19}$, Yolanda Ruiz del Prado ${ }^{20}$, Ignacio Sancho-Val ${ }^{21}$, Pablo Sanjurjo ${ }^{22}$, Miguel Pocovi ${ }^{23}$ and Pilar Giraldo $1,2,3,24,25^{*}$

\begin{abstract}
Background: The enzymatic replacement therapy (ERT) availability for Gaucher disease (GD) has changed the landscape of the disease, several countries have screening programs. These actions have promoted the early diagnosis and avoided many complications in pediatric patients. In Spain ERT has been available since 1993 and 386 patients have been included in the Spanish Registry of Gaucher Disease (SpRGD). The aim of this study is to analyze the impact of ERT on the characteristics at time of diagnosis and initial complications in pediatric Gaucher disease patients.
\end{abstract}

Aim: To analyze the impact of ERT on the characteristics at time of diagnosis and initial complications in pediatric Gaucher disease patients.

Methods: A review of data in SpRGD from patients' diagnosed before 18 years old was performed. The cohort was split according the year of diagnosis ( $\leq 1994$, cohort $A ; \geq 1995$, cohort B).

Results: A total of 98 pediatric patients were included, GD1: 80, GD3: 18; mean age: 7.2 (0.17-16.5) years, 58 (59.2\%) males and 40 (40.8\%) females. Forty-five were diagnosed $\leq 1994$ and 53 $\geq 1995$. Genotype: N370S/N370S: 2 (2.0\%), N370S/L444P: 27 (27.5\%), N370S/other: 47 (48\%), L444P/L444P: 7 (7.1\%), L444P/D409H: 2 (2.0\%), L444P/other: 3 (6.2\%), other/other: 10 (10.2\%). The mean age at diagnosis was earlier in patients diagnosed after $1995(p<0.001)$ and different between the subtypes, GD1: $8.2(0.2-16.5)$ years and GD3: $2.8(0.17-10.2)$ years $(p<0.001)$. There were more severe patients in the group diagnosed before 1994 ( $p=0.045$ ) carrying L444P (2), D409H (2), G377S (1), G195W (1) or the recombinant mutation. The patients' diagnosed $\leq 1994$ showed worse cytopenias, higher chance of bone vascular complications at diagnosis and previous spleen removal. The patients started ERT at a median time after diagnosis of 5.2 years [cohort A] and 1.6 years [cohort B] $(p<0.001)$.

Conclusions: The early diagnosis of Gaucher disease in the era of ERT availability has permitted to reduce the incidence of severe and irreversible initial complication in pediatric patients, and this has permitted better development of these patients. This is the largest pediatric cohort from a national registry.

Keyword: Children, Gaucher Disease, Enzymatic replacement therapy

\footnotetext{
* Correspondence: giraldocastellano@gmail.com

${ }^{1}$ Haematology Department, Miguel Servet University Hospital, Zaragoza,

Spain

${ }^{2}$ CIBER de Enfermedades Raras (CIBERER), Instituto Salud Carlos III, Zaragoza,

Spain

Full list of author information is available at the end of the article
} 


\section{Background}

Gaucher Disease (GD)(OMIM\#230800), the most common inherited lysosomal storage disorder is an autosomal recessively disease; the cause is mutations of the beta-acid-glucosidase gene located in chromosome 1 in the $\mathrm{q} 21$ region [1]. The gene alteration leads to a partial or total lack of glucocerebrosidase (GBA) enzymatic activity in the lysosome, GBA is a hydrolase responsible for the degradation of the glycosphingolipid complex glucosylceramide; the deficiency leads to an accumulation of complex molecules of glucosylceramide inside the lysosomes of reticuloendotelial cells, especially in viscera and bone [2-4].

Clinically, there are 3 sub-types according to neurological involvement. Type 1 GD non-neuronopathyc GD is the most common form of presentation in western countries, and as the name indicates there are no neurological manifestations, type 3 is the second most frequent and the clinical course is characterized by neurological manifestations like ataxia, saccadic eye movements, seizures and neurological impairment, and non-neurological features like heart valves infiltration, kyphosis and other characteristics described elsewhere $[5,6]$, type 2 GD or acute neuronopathic form is the most aggressive presentation of the GD, with severe neurological impairment early in life (newborns to 1 year old) with a short lifespan, usually around 2 years of age [6-8]. Pathophysiology studies reveal that these three types are a continuum of manifestations; from the more severe, the type 2 form, followed by the intermediate disease of type 3 to milder or non-symptomatic phenotypes of some type 1 patients $[9,10]$. These multi-system manifestations are based on the grade of residual GBA enzymatic activity, and the association of some mutations with a high risk of neurologic-involvement $[11,12]$.

The time of diagnosis in GD is variable and directly related to the rate of substrate accumulation and severity presentation [13]. The clinical characteristics of pediatric GD patients are growth retardation, nasal hemorrhages, cytopenias, spleen enlargement and early bone crisis prior to the era of enzyme replacement therapy (ERT) the spleen was frequently removed to improve hematologic parameters, but had a negative impact on bone [14].

After more than two decades of ERT, few reports and guidelines have highlighted the efficacy of an optimal approach to early institution of ERT in pediatric GD patients. The large studies are supported by statistics extrapolating modelling-based studies from data from the International Collaborative Gaucher Group Registry (ICGGR) [15, 16] and several works from national cooperative groups that have summarize information from different cohorts [17-21]. However, the disease manifestations are impacted by the ethnicity/population characteristics and it is important to analyze what we have achieved in every-day clinical practice with current treatment and how the behavior of the disease has changed in the pediatric population, especially in children treated from the first years of life. Focusing on that, a country-based analysis from the Spanish Registry of Gaucher Disease had been performed and presented here.

\section{Methods}

Spanish registry

Since the establishment of the Spanish Registry of Gaucher Disease (SpRGD) coordinated by the "Fundacion Española para el Estudio y Terapeutica de la Enfermedad de Gaucher", (FEETEG), a total of 386 GD patients have been reported in Spain (www.feeteg.org). All of them, or their parents in pediatric cases, had signed informed consent to be part of the registry and permit the use of their data. Approval from the ethics committee and institutional boards were obtained and all aspects are in accordance with the current version of the Helsinki Declaration; the management of the patients was the responsibility of the local physician in charge. From the FEETEG and GD unit, it is encouraged to follow the actual international and European Working Group on Gaucher Disease (EWGGD) recommendations guidelines [22-25] and to perform at least one visit to the GD unit for a general assessment.

\section{Inclusion criteria}

A retrospective review of the available data from patients diagnosed in pediatric age $(<18$ years) and registered in the SpRGD-FEETEG was performed. All patients had a confirmed diagnosis of GD by determination of enzymatic activity B-acid glucosidase activity according to a protocol based on the artificial substrate incubation with 4 methylumbelliferyl-B-D-glucoside-sonicated extracts leukocyte [26], and identification of genetic mutations by sequencing of $G B A$ gene [27]. All biological samples are kept in the Aragon Biobank and included in the Lysosomal Collection. The analyzed variables were: general demographic information, clinical manifestations, biomarkers, visceral \& bone involvement, genotype, therapy and follow-up information. Period of study: May 1993 to April 2016.

\section{Study variables \\ Year of diagnosis}

The cohort was split into 2 subgroups according to the diagnosis made before/in 1994 and after 1994. This decision was taken considering that in 1993, in the Miguel Servet University Hospital, the first adult patient started therapy in Spain. This milestone was 
followed by many efforts to improve the diagnosis and management of GD patients.

\section{Hematologic values}

Considering anemia, the hemoglobin levels $(\mathrm{Hb})$ were defined according to international values (WHO) of normal for age and gender: birth to 6 months, $<10.1 \mathrm{~g} / \mathrm{dL}$; 6 months to 2 years, $<9.5 \mathrm{~g} / \mathrm{dL} ; 2$ years to 12 years, $<10.5 \mathrm{~g} / \mathrm{dL}$; more than 12 years, male, $<12 \mathrm{~g} / \mathrm{dL}$ and female, $<11 \mathrm{~g} / \mathrm{dL}$.

For platelet counts, the normal value was considered above $120 \times 10^{9}$ per $\mathrm{L}$.

\section{Visceral assessment}

Liver and spleen volumes were assessed by physical examination and, when available, also for ultrasound and magnetic resonance. Considering the difficulty in summarizing data, the information was recorded as $\mathrm{cm}$ bellow low marginal costal or as multiples of normal (MN) size when a MRI was carried out.

\section{Biomarkers studies}

At diagnosis and for monitoring of patients chitotriosidase activity and the chemokine-C-motif ligand 18/ Pulmonary-activation-regulated chemokine (CCL18/ PARC) are part of our standard care. In addition we include the genotype of chitotriosidase to determine the presence of the duplication of 24 pair of bases in the 6th exon. The studies were done in plasma as previously described $[28,29]$.

Bone disease assessment: For bone disease evaluation, the history of chronic bone pain, bone crisis, bone lesions or deformities, and bone evaluations by X-ray or MRI prior to starting ERT were noted.

Bone crisis was defined according to the clinical criteria previously described [15], as "pain with acute onset that requires immobilization of the affected area and narcotics for the relief of pain and that may be accompanied by periosteal elevation, elevated white blood cell count, fever, or debilitation that lasts longer than 3 days." Many were reported as suspected crisis and were registered according to the date the physician reported the event as occurring.

For bone mineral density, the results from the densitometry studies dual X-ray absorptiometry (DXA) or ultrasound quantification by broadband ultrasound attenuation (BUA) performed during routine follow-up were included.

\section{Disease severity evaluation}

For this purpose, the Pediatric Gaucher Severity Scoring system (PGS3) previously described by Kallisch $\mathrm{S}$ and Kaplan P. was applied [30].

\section{Statistical analysis}

All the data were collected into a database and analyzed using the SPSS v18.0 program. Because this is a national data registry, many patients were not initially assessed in our clinic, however from each patient, clinical and laboratory data were collected through the physician reports so there was no need to perform any modeling approach.

\section{Results \\ Demographic characteristics}

From the total of 386 patients diagnosed with Gaucher Disease in Spain, 124 (32.1\%) were diagnosed bellow 18 years, $26(20.9 \%)$ were type 2 and the other 98 (79.1\%) suspected to have type 1 disease, of these, 18 (14.5\%) had a genotype other than N370S, developed neurological symptoms and were re-classified as type 3. For this work we considered only GD1 and GD3 patients, $(n=98)$. There was male predominance $(58$, $59,2 \%$ ). The mean age at diagnosis was 7.2 years (range. $0.2-16.5)$, about half of the patients $(48,46.9 \%)$ were diagnosed at 5 years or less. The majority of patients 86 $(87.8 \%)$ had features of GD, and the diagnosis were established in the others $(12,12.9 \%)$ when family screening was performed.

A total of 45 (45.9\%) patients were diagnosis during or before 1994 and 53 (54.1\%) after 1994. Regarding GD3 patients $13 / 18$ were diagnosed after 1994 Fig. 1 . In the first 5 years of the ERT era 22 pediatric patients were diagnosed 4 had GD3. Table 1 summarizes more general characteristics and compares them with the time of diagnosis.

\section{Genotyping \& GD subtypes}

In mutational analysis N370S compound heterozygosis (73, 74.5\%) was the most frequent genotype, of which N370S/L444P was the most common (26, 26.5\%). Only 2 (2.0\%) patients were homozygous for N370S. Regarding the GD3 patients, homozygosity for L444P was the most frequent genotype (7/18, 41.0\%) See Fig. 2.

In general, majority of patients $(70.4 \%, 69$ cases) carried at least one severe mutation (L444P, D409H, RecNi, 84GG, W(-4X), T391P, del55pb, G202R, G195W, P182L, E326K and others). In 20.4\% (20) the severity of the mutation was unknown and the remainder were mild (N370S, G377S), (data not shown) [12].

\section{Baseline evaluation}

During diagnosis or follow-up process 17 patients were splenectomized, three underwent a liver biopsy. There was an association $(p<0.001)$ between the diagnosis before 1994 and splenectomy (14/17 cases), the last three spleen removals occurs in 1998-2001 during the diagnostic process. 


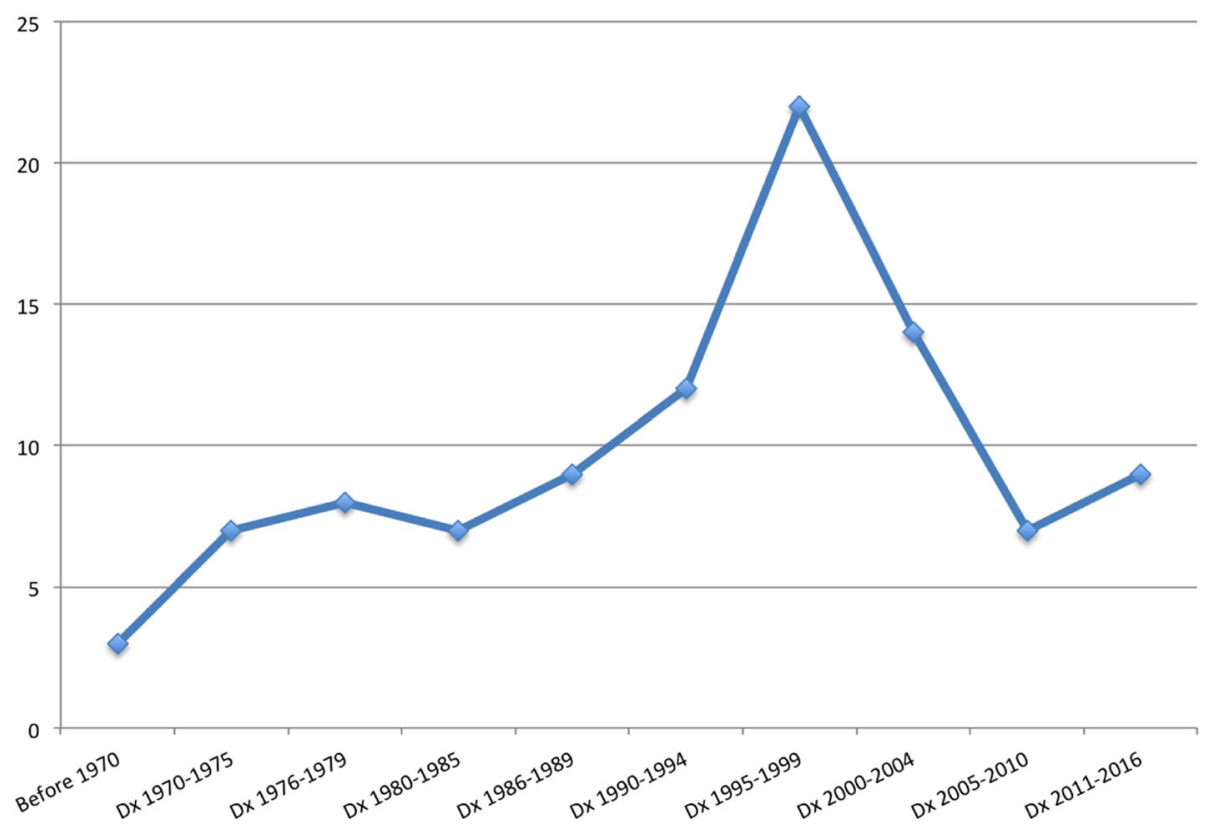

Fig. 1 Timeline of pediatric diagnosed cases

According to the PGS3, in GD1 patients $(n=80)$, more than half had mild disease at baseline (41, 56.3\%), 19 (26.0\%) had moderate and 13 (17.8\%) had severe presentations, there were incomplete data in seven cases. When the PGS3 was applied to GD3 patients 10 (62.3\%) was classified as mild, five (31.3\%) as moderate and 1 $(6.3 \%)$ as severe. "There were more severe patients in the group diagnosed before $1994(p=0.045)$.

\section{Visceral involvement}

Splenomegaly affected all patients; the mean for cohort A was $9.8(2-23) \mathrm{cm}$ below costal rib (BCR) and for cohort B 7.7 (3-19) cm BCR. Hepatomegaly was more prevalent in cohort A.

\section{Hematologic involvement}

Table 1 details the hematological parameters at baseline and compares the values in the two cohorts. In cohort A, $86.7 \%(30$, missing data $=9)$ of patients at diagnosis showed anemia and/or thrombocytopenia, with a mean $\mathrm{Hb}$ value of $9.1(8.0-10.5) \mathrm{g} / \mathrm{dL}$ and platelet count of $80.9(21-112) \times 10^{9} / \mathrm{L}$, cohort B showed $66.7 \%$ (30 cases, 6 missing data) with a mean $\mathrm{Hb}$ concentration of 9.7 $(6.9-10.9) \mathrm{g} / \mathrm{dL}$ and platelets count of 89.3 (44-117) $\times 10^{9} / \mathrm{L}$. The presence of thrombocytopenia was higher in cohort $\mathrm{A}(p<0.001)$ and had lower values $(p=0.02)$ $\left(89.3\right.$ vs $\left.128 \times 10^{9} / \mathrm{L}\right)$.

\section{Bone disease}

There were clear differences between both cohorts $(p<$ 0.001 ), with more severe disease presentation in cohort
A. This was associated with a mean older age at diagnosis for cohort A, $9.0(0.5-16.5)$ years, and for cohort B, $5.7(0.2-15.9)$ years $(p<0.001)$, an undoubted improvement after therapy availability. In the A cohort, a total of $21(50 \%)$ patients reported bone pain before diagnosis, 16 had reported symptoms that resembled a bone crisis and two patients had suffered vertebral fractures. In the cohort B only $12(26.7 \%)$ reported bone pain at diagnosis and seven reported a bone crisis or/and AVN (4). Two L444P homozygous patients developed Norbottnian-like thoracic deformations before 10 years of age and this was reported during the diagnosis process. There was no correlation between the presentation of bone symptomatology and early diagnosis, however the hazard ratio (HR) to manifest a bone complications was 1.7 times higher in cohort A compared to Cohort B with statistically significant $(p=0.025)$ differences between them.

\section{Osteopenia}

In 13 patients form cohort A osteopenia was assessed and found $5(38.5 \%)$ patients at diagnosis and in cohort B 6/16 (37.5\%) assessed patients had osteopenia at diagnosis, there were no differences between the two cohorts. Probably the incidence of osteopenia is under diagnosed due to un-availability of densitometry in all the centers.

\section{Biomarkers}

All the patients showed abnormal values of chitotriosidase, except one with homozygous $24 \mathrm{pb}$ duplication in the CHIT1 gene with 0 activity; 11 patients were 
Table 1 General characteristics comparison according cohorts

\begin{tabular}{|c|c|c|c|c|}
\hline Baseline characteristic & Cohort A N = $45(\%)(\mathrm{Dx} \leq 1994)$ & Cohort B N=53 (\%)(Dx $\geq 1995)$ & Total $(n=98) \mathrm{N}(\%)$ & Diff. \\
\hline Gender M/F (\%) & $27 / 18(60 / 40)$ & $31 / 22(58.5 / 41.5)$ & $58 / 40(59.2 / 48.8)$ & NS \\
\hline Age at Dx (years) & $9.0(05-16.5)$ & $5.7(0.2-15.9)$ & $7.2(0.2-16.5)$ & $p<0.001$ \\
\hline Patient/sibling (\%) & $39 / 6(86.7 / 13.3)$ & 47/6 (88.7/11.3) & $86 / 12(87.7 / 12.3)$ & NS \\
\hline GD1/GD3 & 40/5 (88.9\%/11.1\%) & 40/13 (75.5\%/24.5\%) & $80 / 18(81.6 / 18.4)$ & NS \\
\hline \multicolumn{5}{|c|}{ Pediatric Gaucher Severity Index score } \\
\hline Mild & $22(53.7)$ & $29(60.4)$ & $51(52.0)$ & NS \\
\hline Moderate & $7(17.1)$ & $17(35.4)$ & $24(24.5)$ & NS \\
\hline Severe & $12(29.3)$ & $2(4.2)$ & $14(14.3)$ & $P=0.045$ \\
\hline \multicolumn{5}{|l|}{ Symptoms and signs at diagnosis } \\
\hline Splenomegaly & $45(100)$ & $47(88.6)$ & $92(93.9)$ & NS \\
\hline Hepatomegaly & $27^{*}(60 \%)$ & $40(75.5)$ & $67(68.4)$ & $p=793$ \\
\hline Splenectomy & 15 (39.5\%) & $4(7.8)$ & $19(19.4)$ & $p<0.001$ \\
\hline Anemia or thrombocytopenia & $30(83.3 \%)$ & $30(66.7)$ & $60(61.2)$ & $p=0.047$ \\
\hline Mean $\mathrm{Hb}$ (range) $\mathrm{g} / \mathrm{dL}$ & $11.4(8.0-14.7)$ & $11.3(6.9-13.8)$ & $11.4(6.9-14.7)$ & NS \\
\hline Mean Platelets count (range) & $89.3(21-200) \times 10^{9} / \mathrm{L}$ & $128.3(44-363) \times 10^{9} / \mathrm{L}$ & $112.9(21-363)$ & $p<0.001$ \\
\hline \multicolumn{5}{|l|}{ Other characteristics \& biomarkers } \\
\hline Bone symptomatology & 21 (50) (3missing) & 12 (26.7) (8 missing) & 33 (37.9, 11 missing) & $p<0.001$ \\
\hline Bone pain (only) & $5(11.9)$ & $3(6.7)$ & $8(9.2)$ & NS \\
\hline Vascular bone complication & $16(38.1 \%)$ & $9(20.0)$ & $25(25.5)$ & $p=0.025$ \\
\hline Chitotriosidase & $17,277(1,123-65,497)$ & $11,038(370-38,882)$ & $12,437(370-65497)$ & NS \\
\hline CCL18/PARC & $271(151-552)$ & $1,273(105-3763)$ & $1,023(105-3,763)$ & NS \\
\hline \multicolumn{5}{|l|}{ Genotypes GD1 } \\
\hline N370S/N370S & $1(2.2)$ & $1(1.9)$ & $2(2.0)$ & NS \\
\hline N370S/L444P & $13(28.9)$ & $14(26.4)$ & $27(27.5)$ & NS \\
\hline N370S/Other & $25(55.6)$ & $22(41.5)$ & $47(47.9)$ & NS \\
\hline Other/Other & $1(2.2)$ & $3(6.7)$ & $4(4.08)$ & \\
\hline \multicolumn{5}{|l|}{ Genotypes GD 3} \\
\hline L444P/L444P & $0(0)$ & $7(13.2)$ & $7(7.1)$ & - \\
\hline L444P/Other & $3(6.7)$ & $2(3.8)$ & $5(5.1)$ & NS \\
\hline Other/Other & $2(4.4)$ & $4(7.5)$ & $6(6.12)$ & NS \\
\hline
\end{tabular}

Dx diagnosis, pts patients

heterozygous for $24 \mathrm{pb}$ duplication in CHIT1 gene. The mean values for chitotriosidase showed a wide distribution ranging from 1,123 to $65,497 \mathrm{nmol} /$ mgprot.h. For the cytokine CCL18/PARK all the assessed patients showed high abnormal values ranging from 151 to $3,763 \mathrm{ng} / \mathrm{mL}$. The observed differences between cohorts about the biomarkers values were no statically significant.

\section{Growth assessment}

Eight patients (5 from cohort B) were below the ten percentile for height and gender at diagnosis. There were no significant differences regarding the availability of data to calculate the expected height according parents heights, and there were scanty data from the cohort A patients to establish a proper correlation. From the cohort $\mathrm{B}$, all patients achieved a normal weight and improve the percentile for height to normal patterns during therapy.

\section{GD1 patients $(n=80)$}

Each cohort included 40 GD1 patients with only one N370S homozygous patient in each one and a similar frequency of N370S/L444P patients (Cohort A 13, $32.45 \%$ patients, Cohort B 14, 35.0\% patients), the most common genotype in our population. Based on mutation analysis performed by our group few years ago [11, 12], the majority of patients (33 and 25 cases in cohort A and $B$ respectively) carried an allele with mutations categorized as severe, i.e. $84 \mathrm{GG}$, del55pb and other null 


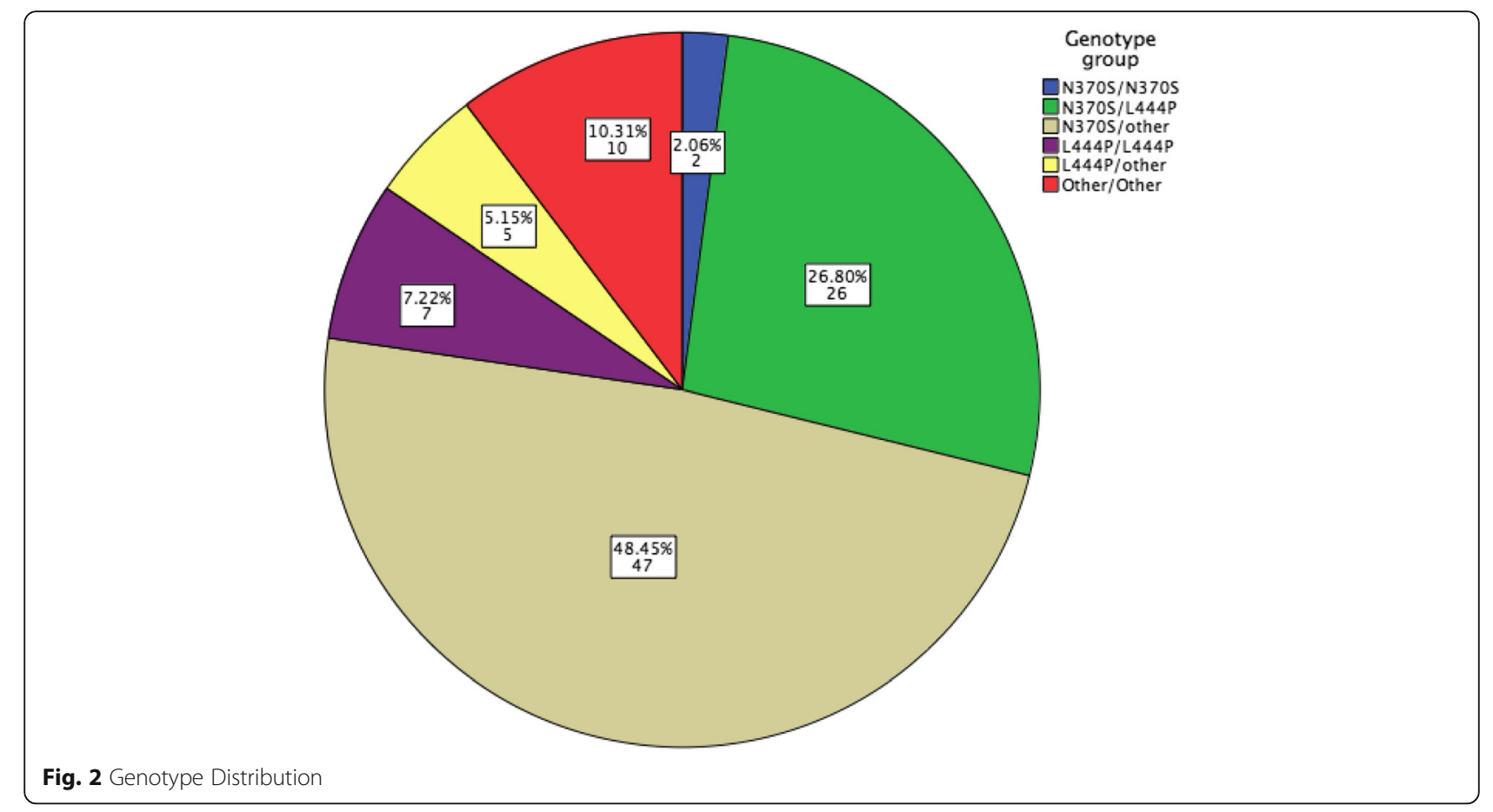

mutations, combined mutations, G195W, G202R, T134P and others (data not published in this article). Regarding the initial symptoms, bone pain was the chief complaint in 20 (50\%) of GD1 patients of cohort A while in Cohort $\mathrm{B}$, spleen enlargement was the most common sign and only 12 (30\%) GD1 patients reported bone pain in cohort B as was previously described.

\section{GD3 patients $(n=18)$}

Five patients from cohort A were GD3, none of them L444P homozygous, but carrying L444P (2), D409H (2), G377S (1), G195W (1) or the recombinant mutation $\mathrm{E} 326 \mathrm{~K}+\mathrm{N} 188 \mathrm{~S}$ (2) with other mutations. In cohort B, 13 patients were GD3, 7 homozygous L444P, 1 L444P with another mutation and 5 with other mutations: homozygous D409H (1), heterozygous D409H (3), RecNi (2), homozygous P266L, heterozygous R463C (1) or G377S (1).

The initial manifestation of GD3 phenotype were strabismus/oculomotor apraxia in 11, psychomotor retardation in 3, myoclonic epilepsy in 3 and thorax in bunker was present in 2 L444P homozygous patients (one of them with saccadic eyes movement).

From the patients whom access to therapy after childhood, in cohort A (31 cases).

\section{ERT access}

The median follow-up (until last contact or 18 years old) was $8.8(0.3-17.5)$ years. During this time 12 patients (26.7\%) of cohort A and 42 (79.2\%) from cohort B initiated ERT during childhood, $(p<0.001)$, globally $55.1 \%$
(54) of cases. The mean global time from diagnosis to ERT for cohort A was: $5.2(0.1-11.9)$ years, and for cohort B: $1.6(0.1-11.2)$ years $(p=0.001)$. The mean age at ERT for cohort A was $12.2(2.9-17.1)$ years and for cohort B: $6.6(0.2-16.0)$ years, $(p=0.001)$.

From the patients whom access to therapy after childhood, in cohort A (31 cases, missing data 2 cases), the mean age was 31.1 (18.4-45.9) years and for cohort B there was only one case (missing data, 11 cases) at 18.1 years.

\section{Discussion}

Besides Ashkenazy's Jewish people, GD is a panethnic and rare disease with a prevalence around 1/70,000100,000 population [6]. In Spain, the Spanish Registry of Gaucher Disease, has reported 386 patients since the establishment of the registry in 1993 for an updated prevalence of $\sim 1: 117,000$ habitants (www.feeteg.org, updated in May 2016).

At the time the diagnostic process was started by pediatricians, family medicine or other specialists, the main manifestations included alterations in blood counts and spleen enlargement; this generally required a hematological consultation, that led to the diagnosis in approximately $75 \%$ of GD patients [31, 32]. In our experience the clinical suspicion based on the presence of organomegaly, anaemia, thrombocytopenia and bone pain had been sufficient to identify the majority of patients, thus avoiding bone marrow aspiration/biopsy.

Around $49 \%$ of the cases (reported from the international GD registry, ICCG) are diagnosed before 
10 years of age and $66 \%$ before 20 years old [15]. Probably an early diagnosis suggests a more aggressive behavior of the disease; in our experience, thanks to the efforts of the FEETEG collaborators, only $34.0 \%$ of children with GD were diagnosed after 10 years, and 38.1\% were diagnosed before 5 years, an important improvement compared to the international experience. When these data are analyzed regarding the availability or not of therapy, after 1994, 75\% of diagnosed patients were bellow 10 years of age and $53.8 \%$ bellow 5 years of age, a clear improvement compared to the international experience. However this sub-analysis has not been made with the ICGG Registry data so cannot be compared.

The availability of enzymatic replacement therapy has changed the landscape of Gaucher disease pediatric patients; the starting point was the worldwide introduction in 1991 of Ceredase (Genzyme, Cambridge, USA) and its replacement by the recombinant form imiglucerase (Cerezyme, Genzyme, Cambrigde, USA) in 1994. It took more than 15 years to add two new enzymes to the therapeutic arsenal, velaglucerase alfa (VPRIV, Shire, Cambrigde, USA), identical to the human enzyme, approved in 2010 and taliglucerase alfa (Protalix, Carmel, Israel) the first plant-based enzyme form approved in 2012. The oral substrate reduction therapy is not yet an option for pediatric patients. Enzyme replacement therapy (ERT) is a non-curative and expensive therapy, is effective in alleviating the visceral manifestations, decreasing bone marrow burden(BMB)/infiltration and preventing bone crisis and bone lesions [33, 34].

Despite the availability of ERT, the key diagnosis features of type 1 Gaucher Disease (GD1) are still the hematologic alterations like low hemoglobin concentration, low platelet count, bone pain/bone crisis, hepato- and splenomegaly [32]. Splenomegaly was almost universal in our pediatric patients presentation, 66.7-83.3\% presented with hematologic alterations and $26.7-50 \%$ with bone manifestations. This is consistent with other reports including the ICGG Registry $[13,30,33]$ and a call for increased awareness in the hematologic field to identified these patients.

The goals of therapy by Pastores et al. [22] are based on the improvements achieved by at least $80 \%$ of the patients treated with enzymatic replacement therapy and this needs to be optimized according the different presentation of the patients. Working with rare disease is a continual challenge, and more in a pediatric setting, the initial problem is, in our experience, to spread widely the knowledge to physicians to recognize the disease and to carry out an extensive baseline assessment to identified the patients in need of therapy and thus avoid complications [35]. Pediatric patients usually reflect more physiologic alterations, with high risk for bone disease and chronic growth failure [15]. The current recommendations for start ERT on children [22], are based in the presence of symptomatology, growth tendency, bone, visceral and hematological alterations. In patients with severe genotypes such L444P and D409H or other genotypes that suggest the diagnosis of a GD3 case, is recommended to initiate therapy as soon as possible. For asymptomatic patients diagnosed bellow 20 years old, it is recommended to start ERT if they are sibling of a patient who requires therapy.

In this respect, it should not be forgotten that the prevalence of genotypes varies among the different populations; in Ashkenazi Jews, N370S is the most frequent mutation [36] and more than the $40 \%$ of those pediatric patients are homozygous for N370S mutation [37], a rare feature in our population (only 2 cases, $2.0 \%$ ). In our cohort there was a predominance of L444P compound heterozygotes and other severe mutations, in line with the more aggressive phenotypes. The data from the international Gaucher Registry also show a lower frequency of N370S/L444P genotype than in our population (14.8\%) and a higher presence of N370S in homozygosity (7.9\%) [15]. This shows the necessity to establish local recommendations based on population characteristics.

In respect to bone crisis, data from the IGGC registry report only $17 \%$ of patients with bone crisis [15], from the UK registry study $26 \%$ GD1 patients reported bone pain [17], but in our cohort, bone alterations were present in $37.9 \%$ (33) of cases, with a clear predominance $(50 \%, 21$ cases) in the cohort diagnosed before 1994 than the patients diagnosed after ERT became available. This is a clear feature of a more severe presentation in our country.

\section{Conclusions}

According to the data including in the Spanish Gaucher Disease Registry the mean age at diagnosis in childhood has changed from 9.0 to 5.7 years in the last 21 years.

In the Spanish population there is greater tendency to severe phenotypes and genotypes in pediatric population compared with ICGGR, probably related to the different genotype spectrum. In our cohort, excluding the siblings, the patients were symptomatic and following the current recommendation in need of therapy. The indications for therapy based on the presence of severe mutations have to be considered according the local spectrum of mutations and behavior of patients. The presence of infrequent mutations like R463C, G377S, P266L and recombinant alleles need to be considered among the indicators for therapy.

Related to bone disease, the higher prevalence of bone complications in children with delayed start of therapy is remarkable, in our study 1.7 times higher in children diagnosed before 1994. 
Comparing the patients diagnosed before or after the availability of ERT this aspect has improved. Physicians need to be careful and recognize patients with less severe manifestation in order to initiate therapy early and avoid the disease complications. These changes are related with the increased awareness of physicians and the efforts made to diagnose patients after ERT became available.

\section{Abbreviations}

AVN: Avascular necrosis; BCR: Below costal ribs; BMB: Bone marrow burden; BUA: Broadband ultrasound attenuation; CCL18/PARC: Chemokine-C-motif ligand 18/Pulmonary-activation-regulated chemokine; CHIT: Chitotriosidase; cohort A: $\leq 1994$; cohort B: $\geq 1995$; DXA: Dual X-ray absorptiometry; ERT: Enzymatic replacement therapy; EWGGD: European Working Group on Gaucher Disease; FEETEG: Fundacion Española para el Estudio y Terapeutica de la Enfermedad de Gaucher; GBA: Glucocerebrosidase; GD: Gaucher disease; GD1: Type 1 Gaucher disease; GD3: Type 3 Gaucher disease; Hb: Hemoglobin; HR: Hazard ratio; ICGGR: International Collaborative Gaucher Group Registry; PGS3: Pediatric Gaucher severity scoring system; SpRGD: Spanish Registry of Gaucher Disease; WHO: World Health Organization

\section{Acknowledgements}

The authors want to acknowledgement to all the collaborators physicians from all the country and their patients for be part of the Spanish Registry of Gaucher Disease, the Spanish Gaucher Disease patients association (AEEFEG) and to the members of the unit of expertise of Gaucher Disease and other Iysosomal storage disorders: Dr. Capablo, Dr. Saez de Cabezon, Dr. Latre, Dr. Roca and Dr. Fraile. The authors want to thanks the Documentary Service of the Miguel Servet University Hospital Library for their support.

\section{Funding}

This work was partially funded by the Fundación Española para el Estudio y Terapeutica de la Enfermedad de Gaucher, FEETEG. FIS 012/01219, FIS PS 15/0616.

\section{Availability of data and materials}

Clinical, analytical, biomarkers, genetic analysis and imaging data are available in the Spanish Gaucher disease Registry. All biological samples are keeping in the Aragon Biobank included in the Lysosomal Collection. Please contact author for data requests.

\section{Authors' contributions}

MA drafted the manuscript; MA, PG, PI, PA reviewed the data and create the database; All the authors have contributed with data to the database, with the creation and approval of the final manuscript.

\section{Competing interests}

The authors declare that they have no competing interests.

\section{Consent for publication}

Not applicable

\section{Ethics approval and consent to participate}

All the patients or their parents in this case registered into the SpRGD had signed an informed consent allowing the use of their data to be used for publications with academic and scientific porpoises. A board approval from the FEETEG foundation, responsible for the SPRGD was required before to perform the study. The Ethical Committee of Aragon approval the study.

\section{Publisher's Note}

Springer Nature remains neutral with regard to jurisdictional claims in published maps and institutional affiliations.

\section{Author details}

${ }^{1}$ Haematology Department, Miguel Servet University Hospital, Zaragoza, Spain. ${ }^{2}$ CIBER de Enfermedades Raras (CIBERER), Instituto Salud Carlos III, Zaragoza, Spain. ${ }^{3}$ Traslational Research Unit, Aragon Institute of Health
Research (IISAragon), Zaragoza, Spain. ${ }^{4}$ Hospital Sant Joan de Deu, Barcelona, Spain. ${ }^{5}$ Pediatric Department, San Jorge Hospital, Huesca, Spain. ${ }^{6}$ Pediatric Department, La Fe University Hospital, Valencia, Spain. ${ }^{7}$ Hospital Clinico Universitario Virgen de la Arrixaca, Murcia, Spain. ${ }^{8}$ Pediatric Department, Manises Hospital, Valencia, Spain. ${ }^{9}$ Haematology Department, Los Arcos del Mar Menor University Hospital, Murcia, Spain. ${ }^{10}$ Haematology Department, Virgen del Puerto Plasencia, Plasencia, Spain. ${ }^{11}$ Haematology Department, Punta Europa Hospital, Cádiz, Spain. ${ }^{12}$ Pediatric Department, Miguel Servet University Hospital, Zaragoza, Spain. ${ }^{13}$ Hospital Universitario Doctor Peset, Valencia, Spain. ${ }^{14}$ Haematology Department, Complejo Hospitalario Albacete, Albacete, Spain. ${ }^{15}$ Pediatric Department, Torrecárdenas Hospital, Almeria, Spain. ${ }^{16}$ Neurology Department, Hospital Universitario Virgen del Rocio, Sevilla, Spain. ${ }^{17}$ Pediatric Department, !2 Octubre University Hospital, Madrid, Spain. ${ }^{18}$ Institut de Recerca Pediàtrica-Hospital Sant Joan de Déu (IRP-HSJD), CIBERER, Barcelona, Spain. ${ }^{19}$ Haematology Department, Virgen del Rocío University Hospital, Sevilla, Spain. ${ }^{20}$ Pediatric Department, Hospital San Millan y San Pedro, La Rioja, Spain. ${ }^{21}$ Haematology Department, Alcañiz Hospital, Teruel, Spain. ${ }^{22}$ Pediatric Department, Cruces University Hospital, Bilbao, Spain. ${ }^{23}$ Biochemistry and Molecular and Cellular Biology Department, Zaragoza University, Zaragoza, Spain. ${ }^{24}$ Spanish Foundation for the Study and Therapy of Gaucher Disease (FEETEG), Zaragoza, Spain. ${ }^{25}$ Unidad de Investigacion Traslacional, Pta Baja, Hospital Universitario Miguel Servet, Paseo Isabel La Catolica 1-3, Zaragoza 50009, Spain.

Received: 25 August 2016 Accepted: 7 April 2017

Published online: 03 May 2017

\section{References}

1. Devine EA, Smith M, Arredondo-Vega FX, Shafit-Zagardo B, Desnick RJ. Regional assignment of the structural gene for human acid betaglucosidase to q42 leads to qter on chromosome 1. Cytogenet Cell Genet. 1982;33(4):340-4.

2. Mehta A. Gaucher disease. Lijec Vjesn. 2007;129 Suppl 3:37.

3. Beutler E, Gelbart T. Glucocerebrosidase (Gaucher disease). Hum Mutat. 1996;8(3):207-13.

4. Brady RO, Kanfer JN, Shapiro D. Metabolism of glucocerebrosides. II. Evidence of an enzymatic deficiency in Gaucher's disease. Biochem Biophys Res Commun. 1965;18:221-5.

5. Sidransky E. Gaucher disease: complexity in a "simple" disorder. Mol Genet Metab. 2004;83(1-2):6-15.

6. Pastores GM, Hugues DA. Gaucher Disease. In: Pagon RA, Adam MP, Ardinger $\mathrm{HH}$, et al., editors. GeneReviews ${ }^{\circledR}$. Seatle: University of Washington; 2000. (Updated 2013 Sep 19) http://www.ncbi.n/m.nih.gov/books/NBK1269/.

7. Charrow J, Andersson HC, Kaplan P, Kolodny EH, Mistry P, Pastores G, Rosenbloom BE, Scott CR, Wappner RS, Weinreb NJ, Zimran A. The Gaucher registry: demographics and disease characteristics of 1698 patients with Gaucher disease. Arch Intern Med. 2000;160(18):2835-43.

8. Giraldo P, Pocoví M, Pérez-Calvo J, Rubio-Félix D, Giralt M. Report of the Spanish Gaucher's disease registry: clinical and genetic characteristics. Haematologica. 2000:85(8):792-9.

9. Goker-Alpan O, Schiffmann R, Park JK, Stubblefield BK, Tayebi N, Sidransky E. Phenotypic continuum in neuronopathic Gaucher disease: an intermediate phenotype between type 2 and type 3. J Pediatr. 2003;143(2):273-6.

10. Wong K, Sidransky E, Verma A, Mixon T, Sandberg GD, Wakefield LK, Morrison A, Lwin A, Colegial C, Allman JM, Schiffmann R. Neuropathology provides clues to the pathophysiology of Gaucher disease. Mol Genet Metab. 2004;82(3):192-207.

11. Alfonso P, Rodríguez-Rey JC, Gañán A, Pérez-Calvo Jl, Giralt M, Giraldo P, Pocoví M. Expression and functional characterization of mutated glucocerebrosidase alleles causing Gaucher disease in Spanish patients. Blood Cells Mol Dis. 2004;32(1):218-25.

12. Alfonso P, Aznarez S, Giralt M, Pocovi M, Giraldo P, Spanish Gaucher's Disease Registry. Mutation analysis and genotype/phenotype relationships of Gaucher disease patients in Spain. J Hum Genet. 2007;52(5):391-6.

13. Grabowski GA, Zimran A, Ida H. Gaucher disease types 1 and 3: Phenotypic characterization of large populations from the ICGG Gaucher Registry. Am J Hematol. 2015;90(S1):S12-8.

14. Weinreb NJ, Goldblatt J, Villalobos J, Charrow J, Cole JA, Kerstenetzky M, vom Dahl S, Hollak C. Long-term clinical outcomes in type 1 Gaucher disease following 10 years of imiglucerase treatment. J Inherit Metab Dis. 2013;36(3):543-53 
15. Andersson H, Kaplan P, Kacena K, Yee J. Eight-year clinical outcomes of long-term enzyme replacement therapy for 884 children with Gaucher disease type 1. Pediatrics. 2008;122(6):1182-90.

16. Gaucher Disease. A strategic collaborative approach from EMA and FDA European Medicines Agency 2014;EMA/44410/2014. http://www.ema. europa.eu/docs/en_GB/document_library/Regulatory_and_procedural_ guideline/2014/05/WC500166587.pdf.

17. Anderson LJ, Henley W, Wyatt KM, Nikolaou V, Waldek S, Hughes DA, Pastores GM, Logan S. Long-term effectiveness of enzyme replacement therapy in children with Gaucher disease: results from the NCS-LSD cohort study. J Inherit Metab Dis. 2014;37(6):961-8.

18. Drelichman G, Ponce E, Basack N, Freigeiro D, Aversa L, Graciela E, Kohan R. Clinical consequences of interrupting enzyme replacement therapy in children with type 1 Gaucher disease. J Pediatr. 2007;151(2):197-201.

19. Bembi B, Ciana G, Mengel E, Terk MR, Martini C, Wenstrup RJ. Bone complications in children with Gaucher disease. Br J Radiol. 2002;75S1:A37-44.

20. El-Beshlawy A, Ragab L, Youssry I, Yakout K, El-Kiki H, Eid K, Mansour IM, Abd El-Hamid S, Yang M, Mistry PK. Enzyme replacement therapy and bony changes in Egyptian paediatric Gaucher disease patients. J Inherit Metab Dis. 2006;29(1):92-8.

21. Ida $H$, Rennert OM, Kobayashi M, Eto Y. Effects of enzyme replacement therapy in thirteen Japanese paediatric patients with Gaucher disease. Eur J Pediatr. 2001;160(1):21-5.

22. Pastores GM, Weinreb NJ, Aerts H, Andria G, Cox TM, Giralt M, Grabowsk GA, Mistry PK, Tylki-Szymańska A. Therapeutic goals in the treatment of Gaucher disease. Semin Hematol. 2004;41(4 Suppl 5):4-14.

23. Kaplan P, Baris H, De Meirleir L, Di Rocco M, El-Beshlawy A, Huemer M, Martins AM, Nascu I, Rohrbach M, Steinbach L, Cohen IJ. Revised recommendations for the management of Gaucher disease in children. Eur J Pediatr. 2013:172(4):447-58.

24. Hollak CE, Aerts JM, Belmatoug N, Bembi B, Bodamer O, Cappellini D, CollinHisted T, Cox TM, Deegan P, Giraldo P, Hughes D, Lukina E, Manuel J, Michelakakis H, Di Rocco M, Vellodi A, Zimran A. Guidelines for the restart of imiglucerase in patients with Gaucher disease: recommendations from the European Working Group on Gaucher disease. Blood Cells Mol Dis. 2010; 44(2):86-7.

25. Cox TM, Aerts JM, Belmatoug N, Cappellini MD, vom Dahl S, Goldblatt J, Grabowski GA, Hollak CE, Hwu P, Maas M, Martins AM, Mistry PK, Pastores GM, Tylki-Szymanska A, Yee J, Weinreb N. Management of nonneuronopathic Gaucher disease with special reference to pregnancy, splenectomy, bisphosphonate therapy, use of biomarkers and bone disease monitoring. J Inherit Metab Dis. 2008;31(3):319-36.

26. Raghavan SS, Topol J, Kolodny EH. Leukocyte beta-glucosidase in homozygotes and heterozygotes for Gaucher disease. Am J Hum Genet. 1980;32(2):158-73.

27. Horowitz M, Wilder S, Horowitz Z, Reiner O, Gelbart T, Beutler E. The human glucocerebrosidase gene and pseudogene: structure and evolution. Genomics. 1989;4(1):87-96

28. Hollak CE, van Weely S, van Oers MH, Aerts JM. Marked elevation of plasma chitotriosidase activity. A novel hallmark of Gaucher disease. J Clin Invest. 1994;93(3):1288-92.

29. Boot RG, Verhoek M, de Fost M, et al. Marked elevation of the Chemokine CCL18/PARC in Gaucher disease: a novel surrogate marker for assessing therapeutic intervention. Blood. 2004;103:33-9.

30. Kallish S, Kaplan P. A disease severity scoring system for children with type 1 Gaucher disease. Eur J Pediatr. 2013;172(1):39-43.

31. Mistry PK, Sadan S, Yang R, Yee J, Yang M. Consequences of diagnostic delays in type 1 Gaucher disease: the need for greater awareness among hematologists-oncologists and an opportunity for early diagnosis and intervention. Am J Hematol. 2007:82(8):697-701.

32. Thomas AS, Mehta A, Hughes DA. Gaucher disease: haematological presentations and complications. Br J Haematol. 2014;165(4):427-40.

33. van Dussen L, Biegstraaten M, Hollak CE, Dijkgraaf MG. Cost-effectiveness of enzyme replacement therapy for type 1 Gaucher disease. Orphanet J Rare Dis. 2014;9:51.

34. van Dussen L, Biegstraaten M, Dijkgraaf MG, Hollak CE. Modelling Gaucher disease progression: long-term enzyme replacement therapy reduces the incidence of splenectomy and bone complications. Orphanet J Rare Dis. 2014;9:112.

35. Mistry PK, Weinreb NJ, Kaplan P, Cole JA, Gwosdow AR, Hangartner T. Osteopenia in Gaucher disease develops early in life: response to imiglucerase enzyme therapy in children, adolescents and adults. Blood Cells Mol Dis. 2011:46(1):66-72.

36. Bronstein S, Karpati M, Peleg L. An update of Gaucher mutations distribution in the Ashkenazi Jewish population: prevalence and country of origin of the mutation R496H. Isr Med Assoc J. 2014;16(11):683-5.

37. Alterescu G, Abrahamov A, Elstein, Zimran A. Children with type 1 Gaucher disease: changing profiles in the 21st century. Zaragoza: 12th European Working Group on Gaucher Disease Congress; 2016.

\section{Submit your next manuscript to BioMed Central and we will help you at every step:}

- We accept pre-submission inquiries

- Our selector tool helps you to find the most relevant journal

- We provide round the clock customer support

- Convenient online submission

- Thorough peer review

- Inclusion in PubMed and all major indexing services

- Maximum visibility for your research

Submit your manuscript at www.biomedcentral.com/submit
C) Biomed Central 